\section{Manyike PC Chinawa JM Aniwada E Udechukwu NP Eke CB Chinawa TA}

DOI:http://dx.doi.org/10.4314/njp.v42i4.8

Accepted: 10th August 2015

Chinawa JM ( $\mathbf{Z})$

Eke CB

Department of Paediatrics,

Chinawa TA, Aniwada E

Department Of Community Medicine, University of Nigeria Teaching

Hospital,

PMB 01129,

Enugu, Enugu State,

Nigeria.

Email: josephat.chinawa@unn.edu.ng

Manyike $\mathrm{PC}^{1}$, Udechukwu NP ${ }^{1}$, College of Medicine, Department of pediatrics, Federal Teaching Hospital Abakiliki, Nigeria.

\title{
Impact of parental sex education on child sexual abuse among adolescents
}

\begin{abstract}
Background: Parental sex education of children is an often overlooked issue in pediatrics, especially in our society where talking about issues concerning sex is regarded as a taboo. Objectives: The objective of this study is to determine the impact of sex education on child sexual abuse among adolescents attending secondary schools in south east Nigeria.

Methods: This is a cross-sectional study that was carried out among children in three secondary schools in Enugu and Ebonyi states of Nigeria. Five hundred and six adolescents who met inclusion criteria were consecutively recruited into our prospective study between June and October, 2014.

Results: Eighty (80\%) of respondents were educated by parents on sex abuse. Of those educated majority was by mother $(46.2 \%)$ and both parents (45.2\%). Most
\end{abstract}

(72.1\%) were not informed that family members or family friends can abuse children and $73.8 \%$ were not told to inform adults if it happens to them. A lower proportion $(37.9 \%)$ of those educated by parents at home was abused. Those educated by parents were 1.23 times less likely to be abused than those not educated. There was significant difference in sex abuse between males and females $(p=0.014)$ while there were no significant difference for age $(\mathrm{p}=0.157)$ and social class $(\mathrm{p}=0.233)$.

Conclusion: Children educated by parents on sexual abuse were less likely to be sexually abused than those not educated. There is no link between socioeconomic class and child sexual abuse among adolescents.

Key words: Parental sex education; adolescents; Nigeria

\section{Introduction}

Adolescence is a stage of development described as a phase of life beginning in biology and ending in society $^{1}$. This period is a dramatic challenge, one requiring adjustment to changes in the self, in the family, and in the peer group. In contemporary society, adolescents experience institutional changes as well ${ }^{2}$. Child sexual abuse among adolescents is a developmental stressor that can have profound, long-term physiologic and psychosocial effects ${ }^{3}$. It has been associated with a variety of health-compromising behavior and health problems, often considered attempts to cope with the trauma engendered by the abuse ${ }^{4}$.

Notably, there exists a relationship between the educational level of parents, sex education and child sexual abuse among adolescents ${ }^{5}$. It is noted that female adolescents whose parents were college graduates were less likely to report recent sexual activity than females whose parents did not complete high school ${ }^{5}$. Also, adolescents (male and female) whose parents were college graduates were less likely to have had sexual intercourse than their counterparts whose parents did not complete high school ${ }^{5}$. Training parents to teach proper names for genitals and other reproductive organs to their children can help to increase youths' empowerment to resist child sexual abuse or disclose it to trusted adults ${ }^{5}$. It can also reduce shame, stigma, and self-blame for youth who have experienced sexual abuse ${ }^{6}$. Educating children can increase family communication about child sexual abuse and strengthen communication between groups of parents in a community ${ }^{6,7}$.

This study is aimed at determining the impact of sex education on child sexual abuse among adolescents. Evaluation of impact of sex education on child sexual abuse among adolescents is under reported in pediatrics 
practice and its importance cannot be downplayed.

Much has not been done on this subject in Nigeria in particular and Africa in general. This study will, therefore, help to determine if there is a difference in existing studies from the present study

\section{Methods \\ Study design}

This is a cross-sectional study that assesses the impact of sex education on child sexual abuse among adolescents attending secondary schools in Enugu and Ebonyi states, south east Nigeria.

\section{Study area}

The study was carried out among children in three secondary schools in Enugu and Ebonyi states of Nigeria.

\section{Study population}

Five hundred and six adolescents who met inclusion criteria were consecutively recruited into our prospective study between June and October, 2014.

Three schools were selected in Enugu and Abakaliki metropolis of Enugu and Ebonyi states, through simple random sampling method. They were all mixed schools.

\section{Study Procedure}

A structured self-administered questionnaire was used to collect information from the adolescents who attend the selected secondary schools. We used the child sexual abuse questionnaire. Adolescents who signed consent and who understood the questionnaire thoroughly were included in this study while adolescents without consent were excluded.

Each family was assigned a socioeconomic class using a recommended method, modified by Oyedeji ${ }^{13}$.

\section{Ethics Statement}

This was obtained from the ministry of education and head of the school authorities and government owned institution where this work was carried out.

\section{Consent}

Informed consent was sought from school teachers, parents/caregivers of potential subjects, including older students in secondary schools, before enrolling them into the study.

\section{Case Selection}

Subjects who fulfilled the inclusion criteria were consecutively enrolled into the study.

\section{Data Analysis}

Data was analyzed using the SPSS statistical package, version 17. The chi-square statistical test and T-test were used for categorical and continuous variables, respectively. Data presentation was in tables.

\section{Results}

Table 1: shows that majority of respondents, 364 (> 70\%), were aged 15-19; 236 (about 47\%),were of lower socio economic class, while there was equal sex distribution. Table 2 shows that about $80 \%$ of respondents were educated by parents on sex abuse. Of those educated majority was by mother $(46.2 \%)$ and both parents (45.2\%). Most (72.1\%) were not informed that family members or family friends can abuse children and $73.8 \%$ were not told to inform adults if it happens to them.

\begin{tabular}{lll}
\hline \multicolumn{3}{l}{ Table 1: socio-demographics of respondents } \\
Variables & Frequency $(\mathrm{n}=506)$ & Percent $(100)$ \\
\hline Age (Years) & & \\
$10-14$ & 132 & 26.09 \\
$15-19$ & 364 & 71.94 \\
$20-24$ & 10 & 1.98 \\
Sex & & \\
Female & 267 & 52.77 \\
Male & 239 & 47.23 \\
Social class & & \\
Upper class & 170 & 33.40 \\
Middle class & 100 & 19.76 \\
Lower class & 236 & 46.64 \\
\hline
\end{tabular}

\begin{tabular}{lll}
\hline \multicolumn{2}{l}{ Table 2: Information by parents on sexual abuse } \\
Variables & $\begin{array}{l}\text { Frequency } \\
\mathrm{n}=506\end{array}$ & Percent \\
\hline $\begin{array}{ll}\text { Ever educated about sex abuse by your } \\
\text { parents }\end{array}$ & \\
Yes & 409 & 80.8 \\
No & 97 & 19.2 \\
Which parent & $\mathrm{n}=409$ & \\
Father only & 35 & 8.6 \\
Mother only & 189 & 46.2 \\
Both & 185 & 45.2 \\
Ever explained by your parents that & $\mathrm{n}=409$ & \\
children may be sexually abused by & & \\
family friends or family members & & \\
Yes & 78 & 19.1 \\
No & 295 & 72.1 \\
I don't remember & 36 & 8.8 \\
Ever informed by your parents to let an & $\mathrm{n}=409$ & \\
adult know if it happened to you & & \\
Yes & 80 & 19.6 \\
No & 302 & 73.8 \\
I don't remember & 27 & 6.6 \\
\hline
\end{tabular}

Table 3 showed that lower proportion (37.9\%) of those educated by parents at home was abused. Those educated by parents were 1.23 times less likely to be abused than those not educated. When adolescents were asked to narrate their feelings after being sexually 
abused, $44.2 \%$ felt threatened or in danger, $42.2 \%$ unable to say no out of embarrassment or shame and $26.6 \%$ had associated physical abuse. Table 4

Table 4: Shows the association between sociodemographic variables, sex abuse experience and regression on socio-demographic variable and sex abuse experience. There was significant difference in sex abuse between males and females $(p=0.014)$ while there were no significant difference for age $(\mathrm{p}=0.157)$ and social class $(\mathrm{p}=0.233)$.It also shows that those aged $15-19$ were 1.33 times and those aged 20-24 years 1.04 times less likely to be abused. Females were 1.53 times more likely to be abused than males. Those from middlelower class were 1.09 and 1.14 times more likely to be abused than higher class

\begin{tabular}{|c|c|c|c|}
\hline Abused & $\begin{array}{l}\text { Not } \\
\text { abused }\end{array}$ & $\begin{array}{c}\text { Test } \\
\text { Statistics } \\
\mathrm{X}^{2}\end{array}$ & $p$ value \\
\hline
\end{tabular}

Ever educated about sex abuse by your parents

\begin{tabular}{|c|c|c|c|c|}
\hline No & & 53 & 1.830 & 0.176 \\
\hline Yes & $\begin{array}{l}155 \\
(37.9)\end{array}$ & $\begin{array}{l}254 \\
(62.1)\end{array}$ & & \\
\hline & & & $\begin{array}{l}95 \% \text { C.I } \\
\text { for OR }\end{array}$ & \\
\hline Variable & OR & Sig. & Lower & Upper \\
\hline Ever ed & $x$ abuse & your 1 & & \\
\hline $\begin{array}{l}\text { No } \\
\text { Yes }\end{array}$ & & & & \\
\hline Yes & 0.813 & 0.377 & 0.514 & 1.287 \\
\hline
\end{tabular}

\begin{tabular}{lll}
\hline \multicolumn{2}{l}{ Table 4: Feelings during sexual abuse } & \\
Variables & $\mathrm{n}=199$ & \\
& Yes & No \\
\hline & $\mathrm{n}(\%)$ & $\mathrm{n}(\%)$ \\
Threatened or in danger & $88(44.2)$ & $111(55.8)$ \\
Unable to say no out of embarrass- & $84(42.2)$ & $115(57.7)$ \\
ment/shame/fear & & \\
Forced to go along for other reasons & $70(35.2)$ & $129(64.8)$ \\
Neither forced nor threatened & $51(25.6)$ & $148(74.4)$ \\
Any physical abuse & $53(26.6)$ & $146(73.4)$ \\
Tried to avoid the situation/s e.g re- & $85(42.7)$ & $114(57.3)$ \\
fusing to go along, running away & & \\
\hline
\end{tabular}

Table 5: Regression on socio-demographic variable and sex abuse experience

95\% C.I.forOR

Socio-demographic variable OR Sig. Lower Upper

Age

$10-14$

$15-19$

20-24

Sex

Female

Male

Social class

Upper class

Middle class

Lower class

$\begin{array}{llll}1.092 & 0.684 & 0.714 & 1.671 \\ 1.140 & 0.601 & 0.697 & 1.866\end{array}$

\section{Discussion}

We noted from this study that children educated by parents on sexual abuse were less likely to be sexually abused than those not educated.

Recent research has suggested that disapproving parental attitudes and sex education toward early sexual activity were significantly correlated with delayed sexual exposure and abuse. It is noted that while disapproving parents communicate their disapproval of risky sexual behavior, a permissive parent acts "in a non-punitive, acceptant, and affirmative manner towards it ${ }^{8,9}$.

It is reported that very few children receive adequate preparation for a safe and satisfying adult sexual life. Open discussion of sexual matters with parents is usually absent at the very time when it is most needed. It is regarded a taboo to discuss issues about sex in our society. This, in turn, is compounded by the pervasive, confusing and conflicting (and predominantly negative) messages received by children about sexuality and gen$\operatorname{der}^{10}$. Mothers will tell their female children that if any man touches their breasts they will become pregnant. These children, with unfettered access to the internet are getting wiser, though, negatively, and, therefore, should be guided.

We observed from this study that mothers educated their children on matters concerning sexual abuse more than the fathers. In one study, mothers are more likely to have detailed discussions with their children about sexual development and contraception. In Africa in general and Nigeria in particular, sex education is seen as a taboo and something too sacred to be discussed with children thus making the children vulnerable when faced with issues that affects they sexuality ${ }^{11}$. Sex education should be carried out by experienced teachers, who themselves have exhibited high moral standards. The first teacher in this case should be the parent, especially mothers ${ }^{12}$. These days it is a well known fact that children find out more about sex on their own. This is because they are more responsive to outside instructors ${ }^{12}$. Parents must create an enabling environment to make the children learn effectively on this issue.

When we asked the adolescents to narrate their feelings after being sexually abused despite receiving adequate sex education; a good number of them felt threatened, in danger and are unable to say no out of embarrassment or shame. It was reported that child sexual abuse makes the adolescents feel betraying their parents, feel powerlessness, losses control, emotionally numb, ashamed and guilty $^{13}$.

It is pertinent to note that parents especially mothers should empathize with their sexually abused children and give them a listening ear.

We noted no correlation between social class, age and sexual abuse in adolescents. This is in tandem with a reportage on a cross sectional study of six countries where no associations with demographic characteristics was noted $^{14}$. This is also supported by other studies done in different areas with different methodologies ${ }^{15,16}$. 


\section{Conclusion}

Children educated by parents on sexual abuse were less likely to be sexually abused than those not educated, though it is not statistically significant. There is no link between socioeconomic class, age and child sexual abuse among adolescents

\section{Authors' contributions}

Dr. JMC and PCM had primary responsibility for protocol development, patient screening, enrolment, outcome assessment, preliminary data analysis, and writing of the manuscript. Dr. PCM, JMC, and EA also supervised the design and execution of the study, and performed the final data analyses.

Conflict of interests: None

Funding: None

\section{References}

1. WHO. Adolescent health. Available from:http://www.who.int/ topics/adolescent_health/ en/.Assessed on 21/12/2014

2. Jennifer R, Ranjini R, Katia F, Jean R. Changes in self-esteem during the middle school years: A latent growth curve study of individual and contextual influences. J. School Psychology.2004;42:243 $-261$

3. Elizabeth MS, Sandra P, Lara LM. The Prevalence of Sexual Abuse Among Adolescents in School. $J$. School Nursing 2003: Volume 19;5

4. N. Kruger, E. Gouws, and A. Dicker, The Adolescents: An Educational Perspective. Only Study Guide for GED-201W, University of South Africa, Pretoria, South Africa, 2011..

5. Santelli, J.S., Lowry, R., Brener, N.D., and Robin, L. The Association of Sexual Behaviors with Socioeconomic Status, Family Structure, and Race/Ethnicity among US Adolescents. American J Public Health. Vol. 90, No. 10, 1582-1587, 2000

6. Kenny MC. Child sexual abuse prevention: psycho educational groups for preschoolers and their parents. J for Specialists in Group Work. 2009;34:24-42.
7. Lampert J, Walsh K. 'Keep telling them until someone listens': understanding prevention concepts in children's picture books dealing with child sexual abuse. Children's Lit in Educ. 2010;41:146-167.

8. Lammers C, Ireland M, Resnick M, Blum R. Influences on adolescents' decision to postpone onset of sexual intercourse: a survival analysis of virginity among youths aged 13 to 18 years. J Adolesc Health 2000; 26: 42-8.

9. Resnick MD, Bearman PS, Blum $\mathrm{RW}$, et al. Protecting adolescents from harm. Findings from the National Longitudinal Study on Adolescent Health. JAMA 1997; 278: 823-32.

10. Sexuality education and the prevention of sexual violence .Obtainable from http:// www.coe.int/t/dg3/children/1in5/ S.onSexualViolence/Gordon.pd. Assessed on 21/12/2014

11. Margaret G, Marjorie S, Philip G. Sexually abused and non abused mothers' discussions about sex and their children's sexual knowledge. Child Abuse \& Neglect1995;19: 985-996
12. Sex Education And The Role OF Mothers - Edo World.Obtainable from www.edoworld.netSex_Education_And_The_Role_OF_ Mothers.html.Assessed on 21/12/2014

13. Feelings after sexual Assault Welcome to South ... Obtainable from www.secasa.com.au/ pages/ feelings-after-sexual-assault. Assessed on 21/12/2014

14. Ismail Y, Joaquim S, Gloria M. A comparative study of the socioeconomic factors associated with childhood sexual abuse in subSaharan Africa. Pan Afr Med J 2012;11:1-17

15. A Brief Synopsis of Child Sexual Abuse from Onset to Adult ...Obtainable from www.yoursocialworker.com/ p-articles/sexual-abuse.htm. assessed on 26th December 2014.

16. Santelli, J.S, Lowry, R., Brener, N.D., and Robin, L. The Association of Sexual Behaviors with Socioeconomic Status, Family Structure, and Race/Ethnicity among US Adolescents. Americ J Public Health. 2000; 90: 1582-1587 